\title{
Perianal Crohn's disease - an active approach
}

\author{
G HELLERS, MD, PHD
}

G Hellers. Perianal Crohn's disease - an active approach. Can J Gastroenterol 1993;7(2):272-274. There are very different opinions about the best surgical method for treatment of anal fistulae in Crohn's disease. One opinion is that surgery should be avoided because it often results in large nonhealing ulcers and fecal incontinence. Our experience, however, is that patients with local tenderness should be treated surgically and that such treatment often is successful. Factors such as activity of the intestinal lesion, degree of rectal involvement and type of fistula are important for choice of surgical method. Setons have a key role in surgical treatment; they may be used either as definite treatment just to achieve drainage or as a method of transforming a fistula into a shape that will allow excisional surgery and healing.

Key Words: Anal fistulae, Crohn's disease, Surgery

\section{Maladie de Crohn périanale - approche active}

RÉSUMÉ: Les opinions different grandement à propos de la meilleure méthode de traiter chirurgicalement la fistule anale dans la maladie de Crohn. L'une des opinions veut que la chirurgie soit évitée parce que elle souvent résulte en des ulcères chroniques et en une incontinence fécale. Selon notre expérience cependant, les patients qui présentent une sensibilité locale doivent être traités chirurgicalement et ce traitement réussit souvent. Les facteurs comme l'activité des lésions intestinales, le degré d'atteinte rectale et le type de fistule sont importants pour le choix de l'intervention chirurgicale. Les sétons jouent un rôle central dans le traitement chirurgical. Ils peuvent être utilisés soit en traitement définitif, simplement pour obtenir un drainage ou pour façonner la fistule et lui donner une forme qui permettra une chirurgie excisionnelle et la cicatrisation.
$\mathrm{T}$

HE ASSOCIATION BETWEEN CROHN'S

disease and anal lesions has been

known for a long time. As early as 1938,

Penner and Crohn (1) reported on 20 patients with anal fistulae among 110 patients with intestinal Crohn's disease. Anal fistulae can also be the first manifestation of Crohn's disease (2).
Department of Surgery, Karolinska Institute, Huddinge, Sweden

Correspondence and reprints: Dr G Hellers, Karolinska Institute, Huddinge University

Hospital, S-14186 Huddinge, Sweden
Crohn's fistulae are in many cases asymptomatic apart from drainage of usually small amounts of pus. The internal opening is often not located in the posterior midline and the external openings are often multiple. The different openings, in particular the internal opening, sometimes develop into deep penetrating or cavitating ulcers rather than to small, well-defined orifices as seen in non-Crohn's fistulae. The fistulous tracts are often less well defined and the fistula system may therefore be difficult to probe. High fistulae and rectovaginal fistulae are not uncommon and in many cases associated with Crohn's disease with rectal involvement.

\section{PREVALENCE}

The prevalence reported in the literature is highly variable. Figures ranging from about $10 \%$ up to almost $100 \%$ have been given. The first major report was by Fielding in 1975 (3), in which he reported anal lesions (mostly fistulae) in $70 \%$ of patients with Crohn's disease. From St Marks Hospital a $34 \%$ prevalence (4) has been reported, and from the Lahey Clinic a $22 \%$ prevalence (5). In an epidemiological study from Stockholm the prevalence was found to be $22 \%$. The prevalence of fistulae is closely related to the site of the primary intestinal lesion with a prevalence below $10 \%$ in 
cases with small bowel Crohn's disease and well above $50 \%$ in patients with large bowel disease and even higher in patients with obvious rectal involvement (6).

\section{NATURAL HISTORY}

In a study of the appearance of fistulae in relation to the natural history of disease, it was found that $36 \%$ of the patients had an anal lesion as the initial manifestation of disease (5). In the same study, as many as $26 \%$ of patients had had their intestinal disease for more than 10 years before the anal lesion appeared. In 18\% the lesion manifested within the first year following diagnosis. There is also a relationship between activity of disease and the appearance of fistulae. It is uncommon for fistulae to appear in patients with quiescent disease. An already existing fistula may, however, continue to be mildly active, even if the intestinal lesion goes into remission.

Spontaneous healing of Crohn's fistulae occurs when the intestinal lesion is inactive. In the study from Stockholm more than $50 \%$ of fistulae healed when the primary lesion was in the small bowel and in about $40 \%$ if there was a combined ileocolic lesion (6). If, however, the intestinal lesion becomes active again and there is a recurrence, many of the fistulae that have healed spontaneously will reopen again. In patients with obvious rectal involvement spontaneous healing is rare.

\section{SURGERY}

The opinion about the best surgical approach for anal fistulae in Crohn's disease is highly varied. Strategies varying from "Hands off the anus" (7) to very aggressive treatment (8) have been suggested. The first approach is probably based on the experience that indiscriminate surgery for Crohn's anal lesions may be followed by a considerable morbidity which includes fecal incontinence, anal stenosis and huge nonhealing perianal wounds. Admittedly many patients have no symptoms and in those cases surgery is by no means necessary. There are, however, a number of patients that are for various reasons symptomatic and these patients may be helped by surgery. The key to success in these cases is optimal selection of cases and choice of surgical method.

The most important factors for appropriate selection of cases are: presence of local sepsis or abscess; activity of intestinal disease; rectal involvement of disease; type of fistula(e); and surgical method.

Local sepsis: Patients with fistulae should be treated on the basis of symptoms rather than on the basis of objective findings. The anal lesion may look severe but the patient has remarkably few symptoms. Symptoms, varying from local tenderness to severe pain are, however, an indication that action should be taken. Patients with local tenderness may look remarkably normal from the outside and drainage from existing fistulae may be minimal.

It is important to examine patients with local tenderness under general anaesthesia. When the examination is carried out it is helpful to use ultrasound because Crohn's fistulae are in many cases more difficult to localize than non-Crohn's fistulae. When the collection of pus is identified it should be drained by the simplest possible incision (9). Large wounds should be avoided. In the acute phase the internal opening may be difficult to identify and the fistulous tract is often difficult to probe. If the tract and the internal opening cannot be found with ease it is better to postpone this. The patient may be put under general anesthesia again a week or so later. At this moment the acute infection and edema has usually decreased so that the tract can be identified fairly easily.

Activity of intestinal disease: There is evidence that the prognosis of fistula is related to the activity of disease $(6,10)$. Active disease seems to prevent or delay healing, although there have been reports to the contrary (11). A poor outcome with nonhealing following surgery seems to be related to active disease. It is therefore wise to do as little surgery as possible in the acute phase and wait with definitive surgery until the intestinal lesion is in remission. As mentioned above, the main objective in the acute phase is to treat local sepsis. Rectal involve of disease: Severe rectal involvement often leads to rectal excision $(6,12)$. These patients have often had multiple unsuccessful limited procedures for perianal fistulae. In many cases the rectal involvement is also combined with generalized intestinal disease.

Several methods have been proposed in order to avoid rectal excision. The two most common methods used are maintenance metronidazole treatment and fecal diversion. Long term treatment with metronidazole bas been described to give both symptomatic and objective improvement (13). Relatively high doses are, however, required and most patients can therefore not tolerate the treatment because of side effects. If the drug is reduced to tolerable levels, the disease in recurs in most cases.

Fecal diversion has been most consistently tried in Oxford, United Kingdom. The Oxford group reported on 32 split ileostomies (14). In 11 cases perianal disease was the principal indication and in the remaining $21 \mathrm{a} \mathrm{sub}$ sidiary reason. After diversion most patients healed spontaneously or after local surgical repair. The long term results were, however, not particularly impressive. After three years only six patients had had their bowel continuity restored while the remaining were either still dysfunctioned or had undergone proctocolectomy. Severe rectal involvement seems to be an indicator of poor outcome.

Type of fistulae: There are different surgical approaches for the various types of fistula. In the case of nonCrohn's fistulae the size and extension of the fistulae does not have so much influence on the choice of method. In the case of Crohn's fistulae it is often wise to choose very conservative methods in patients with extensive fistulous systems such as patients with high fistulae or rectovaginal fistulae. In patients with less extensive systems, more active approaches can be chosen. About $75 \%$ of such wounds will heal within three months provided that the intestinal lesion is not active (11). 
Surgical method: A range of various surgical methods have been suggested varying from very conservative (7) to very active (8). In Stockholm, the author's group has for many years had a cautious/active approach. These have been very cautious in patients with active intestinal disease and used a stepwise procedure. Patients with local tenderness have been examined under general anesthesia and any localized pus has been drained. They then try to identify the fistulous system in a more quiescent stage and insert setons in all tracts. They prefer noncutting setons that are loosely tied. The seton should be rather thick

\section{REFERENCES}

1. Penner A, Crohn B. Perianal fistulae as a complication of regional ileitis. Ann Surg 1938;108:867-73.

2. Gray BK, Lockhart-Mummery HE, Morson BC. Crohn's disease of the anal region. Gut 1965;6:515-24.

3. Fielding JF. Perianal lesions in Crohn's disease. J Roy Coll Surg (Edin) 1972;17:32-7.

4. Marks CG, Ritchie JK, LockhartMummery HE, Anal fistulae in Crohn's disuse. Br J Surg 1981;68:525-7.

5. Williams DR, Coller JA, Corman ML, Nugent FW, Veidenheimer MC. Anal with a plain surface. Even thin rubber tubes may be used. Woven suture material should not be used since such sutures have a cutting tendency even if they are loosely tied. If there are no further septic complications the setons could be left in place for considerable periods of time. There are several patients who have had their setons for more than five years. There have been several reports in the literature with similar successful experiences of seton management $(15,11)$.

The primary aim of seton management is to drain the fistulous system and thus to keep the patient symptom free. In some cases is may also be a slow

complications in Crohn's disease. Dis Colon Rectum 1981;24:22-4.

6. Hellers G, Bergstrand O, Ewerth S, Holmström B. Occurrence and outcome after primary treatment for anal fistulae in Crohn's disease. Gut 1980;21:525-7.

7. Alexander-Williams J, Buchman P. Perianal Crohn's disease. World J Surg 1980;4:203-8.

8. Athanasiadis S, Girona J. New methods of treatment of perianal fistulae in Crohn's disease. Langenbeck Arch Surg 1983;360:119-32.

9. Pritchard TJ, Schoetz DJ, Roberts PC, Murray JJ, Coller JA, Veidenheimer MC. Perirectal abscess in Crohn's road to definitive healing. If the intestinal lesion is kept under control, the fistulous tract with its seton will slowly move towards the skin surface. Over the years a complex system can in this manner be converted into a more simple system. It is often possible in such cases, after a couple of years, to excise the system in a conventional manner and achieve a normal wound healing. In the case of high fistulae, it is often possible to keep patients asymptomatic by the use of the seton technique. The seton technique can also be used in rectovaginal fistulae, but in that case results have been more questionable.

disease. Dis Colon Rectum 1990;33:933-7.

10. Heuman R, Bolin T, Sjödahl R, Tagesson C. The incidence and course of perianal complications and arthralgia after intestinal resection with restoration of continuity in Crohn's disease. $\mathrm{Br}$ J Surg 1981;68:528-30.

11. Williams JG, Rothenberger DA, Nemer FO, Goldberg SM. Fistulain-ano in Crohn's disease. Dis Colon Rectum 1991;34:378-84.

12. Williams JG, Hughes LE. Abdominoperianal resection for perianal Crohn's disease. Dis Colon Rectum 1990;33:402-7. 


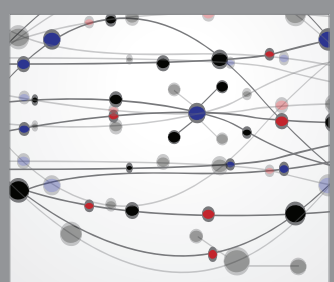

The Scientific World Journal
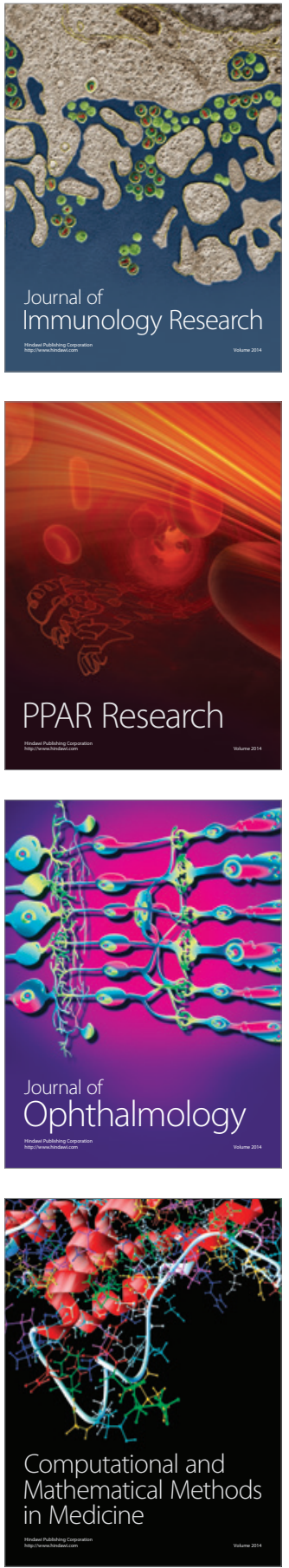

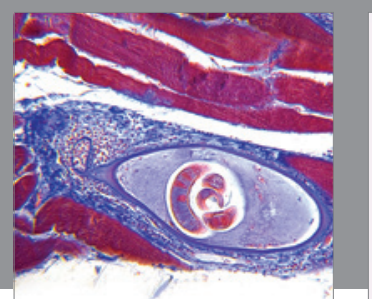

Gastroenterology Research and Practice

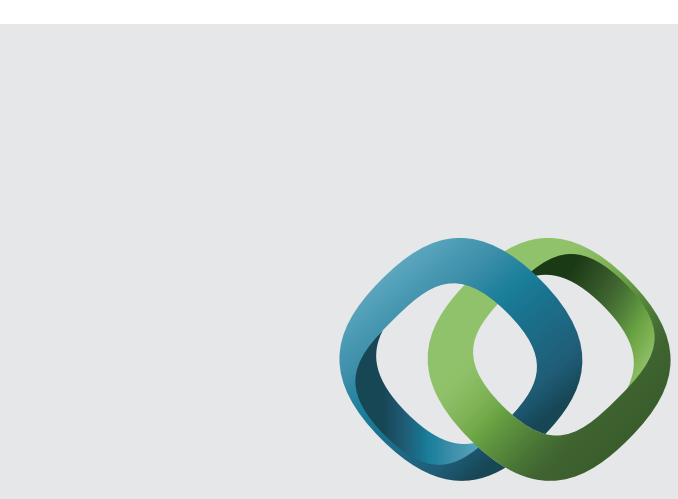

\section{Hindawi}

Submit your manuscripts at

http://www.hindawi.com
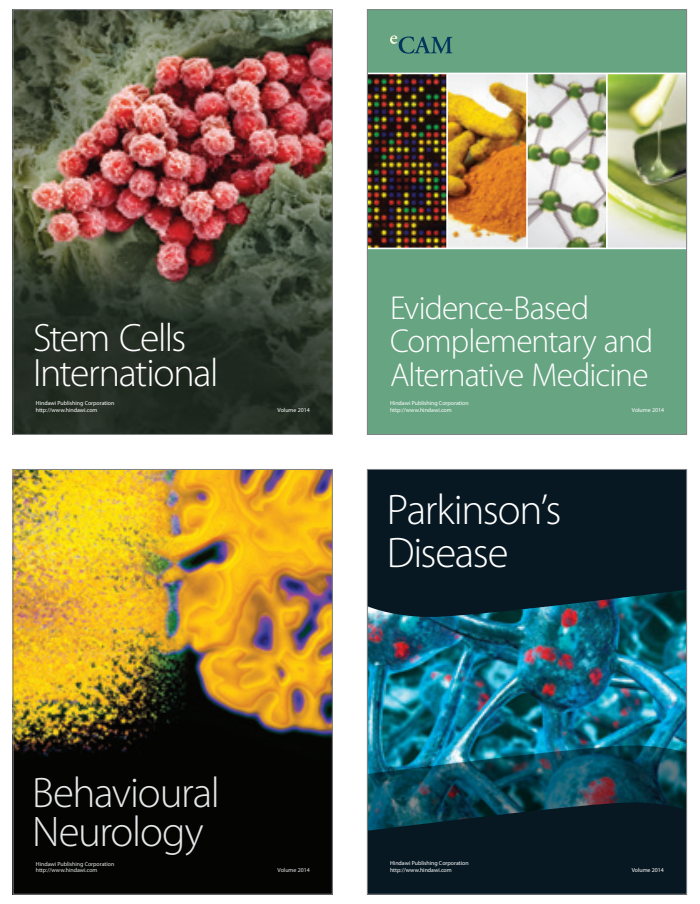
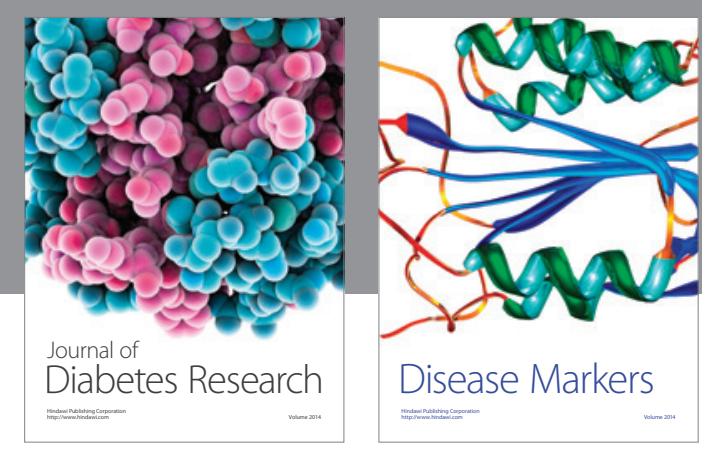

Disease Markers
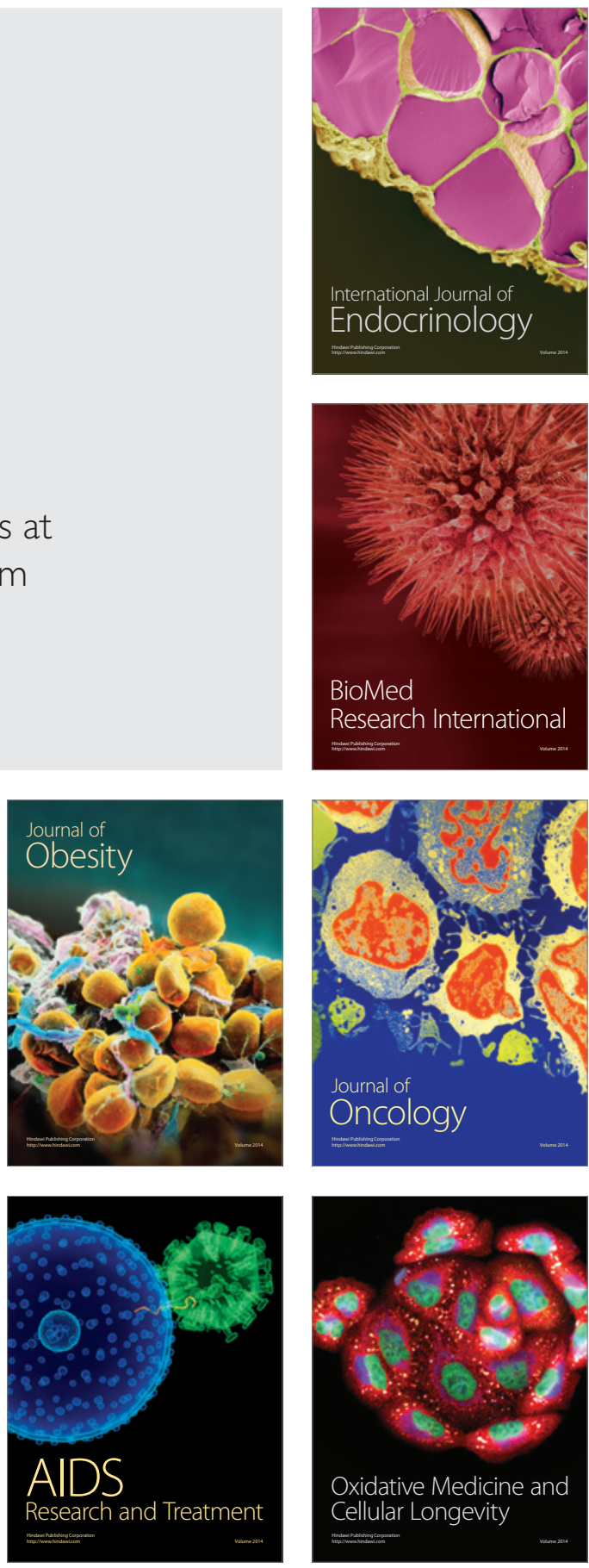